\title{
Surgical Treatment of Secondary Hyperparathyroidism in Surgery B of Chu of Point G
}

\author{
S. Diallo ${ }^{*}$, O. Sacko², M. Sissoko² , A. Kanté ${ }^{3}$, A. Coulibaly ${ }^{1}$, L. Soumarée, \\ B. Coulibaly ${ }^{1}$, M. Camara ${ }^{2}$, D. Traoré ${ }^{1}$, N. Ongoiba ${ }^{1}$ \\ ${ }^{1}$ Service of Surgery B, CHU Point G, Bamako, Mali \\ ${ }^{2}$ Service of Surgery A, CHU Point G, Bamako, Mali \\ ${ }^{3}$ Laboratory of Anatomy, Faculty of Medicine and Odontostomatology, Bamako, Mali \\ Email: *diallosk3@yahoo.fr
}

How to cite this paper: Diallo, S., Sacko, O., Sissoko, M., Kanté, A., Coulibaly, A., Soumaré, L., Coulibaly, B., Camara, M., Traoré, D. and Ongoiba, N. (2019) Surgical Treatment of Secondary Hyperparathyroidism in Surgery B of Chu of Point G. Surgical Science, 10, 355-361.

https://doi.org/10.4236/ss.2019.1010039

Received: August 11, 2019

Accepted: October 6, 2019

Published: October 9, 2019

Copyright $\odot 2019$ by author(s) and Scientific Research Publishing Inc. This work is licensed under the Creative Commons Attribution International License (CC BY 4.0).

http://creativecommons.org/licenses/by/4.0/

(c) $\underset{\mathrm{EY}}{\mathrm{C}}$ Open Access

\begin{abstract}
Purpose: To describe the epidemiological, clinical and therapeutic aspects of secondary hyperparathyroidism inrenal failure chronic. Patients and methods: We collected 11 cases of hyperparathyroidism secondary to renal failure terminal operated in the Service of surgery B of the Central Hospital University of Point G between December 2016 and November 2018. Results: The sex ratio was 0.22 in favor of women. The average age of the patients was 43 or 27 years with extremes of 63 and 25 years. Secondary hyperparathyroidism in renal failure chronic represented $1.9 \%$ of interventions to cold in the Service of surgery B. $100 \%$ of patients (11/11) were haemodialysis. $100 \%$ of the patients had clinical and biological signs. 45.5\% (5/11) had radiological signs. The average rate of parathyroid hormone was $2413.51 \mathrm{pg} / \mathrm{ml}$ with extremes of $1264 \mathrm{pg} / \mathrm{ml}$ and $3616 \mathrm{pg} / \mathrm{ml}$. The reference value was $15-65 \mathrm{pg} / \mathrm{ml}$. The surgical technique of choice was the $7 / 8$ th parathyroidectomy in $100 \%$ of cases. The postoperative were simple in $81.8 \%$, and complicated in $18.2 \%$. There were no death. The average duration of postoperative follow-up was 6 months. After surgery, $50 \%$ of patients (5/10) had normal levels of parathyroid hormone and 50\% (5/10) made a persistent hyperparathyroidism. Conclusion: Secondary hyperparathyroidism is a frequent complication in renal insufficient chronic in hemodialysis. Surgery is indicated in the resistant cases of medical treatment. The $7 / 8$ th parathyroidectomy is the surgical technique of choice. The rate of post operative complications is higher in our context.
\end{abstract}

\section{Keywords}

Secondary Hyperparathyroidism, Treatment, Surgery 


\section{Introduction}

Hyperparathyroidism is the set of clinical, biological and anatomical demonstrations as a result of hyper secretion of parathyroid hormone (PTH) by the parathyroid glands.

Hyperparathyroidism can be primary (parathyroid adenoma in $80 \%-85 \%$, primitive hyperplasia in $14 \%-15 \%$ and carcinoma $<1 \%$ ), secondary (compensatory hyperplasia due to a decline in the rate of calcium in the renal insufficient chronic), or tertiary (autonomous hyperactivity of the parathyroid). Secondary hyperparathyroidism is a common complication in chronic renal failure [1]. It is an inevitable condition in chronic renal insufficient patients at the stage of hemodialysis; because it is the result of an alteration extended responsible for kidney function of phosphocalcic metabolism disorder. The increase in the secretion of PTH trained parathyroid hormone, a hypocalcemie, a hyperphosphoremie, a deficiency in vitamin $\mathrm{D}$ [1].

The diagnosis is mentioned before the clinical and radiological components but the confirmation is based on the immunoassay of the serum of parathyroid hormone (PTH serum). The hearing is before any medical; however these therapies are limited by their lack of effectiveness in the long term. The morbi-mortality is linked to osteo-articular and cardiovascular complications. When the hyperparathyroidism becomes uncontrolled, the parathyroidectomy remains the reference. The purpose of this work was to describe the epidemiological, clinical and therapeutic aspects of hyperparathyroidism secondary to chronic renal failure in the Service of surgery B of the Central Hospital University of Point G.

\section{Patients and Methods}

It was a retro-prospective descriptive and analytical study which took place in the Service of surgery B of CHU of Point G from December 2016 to November 2018 or a duration of 24 months. We have included all patients who have been operated for secondary hyperparathyroidism confirmed by dosage of the parathyroid hormone in the Service of surgery B of the Point G Academic Hospital Center.

Have not been included in this study:

- Patients with non-exploitable records;

- Other hyperparathyroidism (primary and tertiary);

- Secondary hyperparathyroidism medically treated (not operated). Judging criteria:

We have defined secondary hyperparathyroidism in chronic renal failure according to the international recommendations of Kidney Disease Improving Global Outcome (KDIGO).

At the terminal stage of chronic renal failure, we target to maintain between 2 to 9 times the upper limit of the standard of the dosage used (Table 1).

The reference value of the Parathyroid hormone in the blood was 15 - 65 
$\mathrm{pg} / \mathrm{ml}$ in a laboratory of Bamako.

To make the diagnosis we relied on the clinical, radiological and biological arguments.

Cervical ultrasound has allowed us to objectify the pathological glands.

The surgical indication was asked before the failure of medical treatment with a rate of PTH over $1000 \mathrm{pg} / \mathrm{ml}$.

All patients were dialyzed 24 hours before surgery and immediately after surgery.

Post operative follow-up was based on the dosage of the parathyroid hormone and standardization in the range of 2 to 9 times (the reference value of the parathyroid hormone in the blood of the laboratory was $15-65 \mathrm{pg} / \mathrm{ml}$ ) either 130 $585 \mathrm{pg} / \mathrm{ml}$ (Table 2).

The postoperative follow-up of the patients was done immediately Postoperatively, at 1 week, 1 month, 3 months, 6 months, 1 year, 2 years as shown in Table 3.

The minimum duration of patient follow-up was 6 months:

Data processing and analysis were done on the Microsoft Windows software version 2007, SPSS 12.0 for Windows. The probability test used was $\mathrm{Chi}^{2}$ with a threshold of meaning $\mathrm{p}<0.05$.

Table 1. Definiton of secondary hyperparathyroidism in renal failure chronic according to international recommendations of Kidney Disease Improving Global Outcome (KDIGO).

\begin{tabular}{cc}
\hline KDIGO & PTH (pg/ml) \\
\hline Subjects without renal failure & $10-60$ \\
Insufficient renal terminal & 2 to 9 times the limit superior of the normal \\
\hline
\end{tabular}

Table 2. Distribution of patients for secondary hyperparathyroidism according to the results of biological pre-operative balance.

\begin{tabular}{|c|c|c|c|c|c|}
\hline $\begin{array}{c}\text { Patient } \\
\mathrm{N}^{\circ}\end{array}$ & $\begin{array}{c}\text { Calcemie } \\
\text { going }= \\
2.15-2.55 \\
\mathrm{mg} / 1\end{array}$ & $\begin{array}{c}\text { Phosphoremie } \\
\text { going }= \\
2.50-4.50 \\
\mathrm{mg} / 1\end{array}$ & $\begin{array}{c}\text { Rate of parathyroid } \\
\text { hormone (PTH) } \\
\text { is }=15-65 \\
\mathrm{pg} / \mathrm{ml}\end{array}$ & $\begin{array}{c}\text { Alkaline } \\
\text { phosphatase } \\
\text { (PAL) going = } \\
35-104 \text { UI/1 }\end{array}$ & $\begin{array}{c}\text { Total } \\
\text { Vitamin-D } \\
\text { will }=20-40 \\
\mathrm{ng} / \mathrm{ml}\end{array}$ \\
\hline 1 & 2.61 & 3.09 & 3250.12 & 205 & 35.35 \\
\hline 2 & 2.09 & & 1307 & 240 & \\
\hline 3 & 2.29 & 3.38 & 1257 & 347 & 54.05 \\
\hline 4 & 2.50 & 5.30 & 3351 & 120 & 34.36 \\
\hline 5 & 2.31 & 5 & 2269 & - & 27.49 \\
\hline 6 & 2.27 & 3.78 & 2273 & 187 & 15.08 \\
\hline 7 & & & 3325 & & \\
\hline 8 & & & 3616 & & \\
\hline 9 & 2.46 & 7.07 & 1793 & & 30.74 \\
\hline 10 & 3.32 & 4.42 & 2843.50 & & 18.06 \\
\hline 11 & 2.18 & 3.03 & 1264 & & \\
\hline Moyenne & & & 2413.51 & & \\
\hline
\end{tabular}


Table 3. Distribution of patients for secondary hyperparathyroidism according to the results of biological immediate post operative balance and long-term.

\begin{tabular}{cccccccccc}
\hline $\begin{array}{c}\text { Patient } \\
\mathrm{N}^{\circ}\end{array}$ & $\begin{array}{c}\text { Rate of } \\
\text { PTH pre } \\
\text { operating }\end{array}$ & $\begin{array}{c}\text { Rate of PTH } \\
\text { post surgery } \\
\text { immediate }\end{array}$ & 1 week & 1 month & 3 months & 6 months & 1 year & 2 years \\
\hline 1 & 3250.12 & 665.50 & 986.10 & 1056 & 400 & 462.8 & 507.7 & 585 \\
2 & 1307 & & & 915 & & 1007 & 1057 & \\
3 & 1257 & & & & 480 & 457 & & \\
4 & 3351 & 719.33 & & & & 768.1 & 630 & \\
5 & 2269 & & & 2094 & & & 1675 & \\
6 & 2273 & 934.16 & & & 509 & 324 & 465 & \\
7 & 3325 & 2504 & 3024 & & & 2922 & 3000 & \\
8 & 3616 & 3501 & 2215 & & & 2886 & 3435 & \\
9 & 1793 & 349.70 & & 1063 & 821.9 & 714.5 & 428.2 & \\
10 & 2843.50 & 1678.6 & & & 118.9 & 114.5 & & \\
11 & 1264 & 7.5 & & & 104.8 & 131.7 & & \\
\hline
\end{tabular}

\section{Results}

We have collected 11 cases of secondary hyperparathyroidism in renal failure terminal operated in the service.

The sex ratio was 0.22 for women either 9 women (81.80\%) and 2 men (18.20\%).

The average age of the patients was 43.27 years with extremes of 25 and 63 years.

Secondary hyperparathyroidism in renal failure chronic terminal represented $1.9 \%(11 / 581)$ of interventions to cold in the Service of surgery B.

$81.8 \%$ of the patients $(9 / 11)$ were hypertensive and $100 \%$ of patients $(11 / 11)$ had an IRC.

$100 \%$ of patients were made for FAV once or twice.

Hemodialysis has been the type of dialysis performed in $100 \%$ of patients.

Clinical signs were osteoarticular (arthralgia, bone pain) in $91 \%$ of cases (10/11), neuro-muscular events (cramping, weakness) in $91 \%$ of cases $(10 / 11)$, skin events (pruritus, calphylaxie) in $18.2 \%$ of cases (2/11), lesions of scraping in $18.2 \%$ of cases (2/11), deformations of members in $18.2 \%$ of cases $(2 / 11)$, an asthenia in $100 \%$ of cases. The radiological signs were a bone resorption in $18.2 \%$ of cases $(2 / 11)$, a bone demineralization in $9.1 \%$ of cases $(1 / 11)$, a brown tumors in $9.1 \%$ of cases $(1 / 11)$, a fracture in $9.1 \%$ of cases $(1 / 11)$.

The ultrasound of the neck all patients objectified a parathyroid nodule in $45.5 \%$ cases $(5 / 11)$, multiple nodules parathyroid in $27.3 \%$ of the cases $(3 / 11)$, hyperplasia broadcasts parathyroid + below goiter in $18.2 \%$ of cases $(2 / 11)$, a parathyroid nodule + an isthmic intra nodule in $9.1 \%$ of cases $(1 / 11)$.

The echo heart was carried out in $18.2 \%$ of cases $(2 / 11)$, cervical scanner in 
$18.2 \%$ of cases $(2 / 11)$, the chest radiography in $18.2 \%$ of cases $(2 / 11)$. We did neither the scintigraphy nor the extemporaneous examination of the operating room nor the per operative dosage of the parathyroid hormone.

In pre-operative the average rate of PTH was $2413.51 \mathrm{pg} / \mathrm{ml}$ and ranged from 1257 and 3616 as shown in Table 2.

The previous cervicotomy transversal type Kocher has been the path of surgical first performed in $100 \%$ of cases.

The surgical technique performed was the subtotal parathyroidectomy or the $7 / 8$ th at $100 \%$ of the patients. It consisted of the complete removal of the 3 parathyroid glands (of pathological aspect) and half of the last (of healthy appearance) parathyroid gland. We have not conducted any total parathyroidectomy according to Wells.

As gestures associated with the parathyroidectomy, we realized the subtotal thyroidectomy in $18.2 \%$ of cases $(2 / 11)$, the left isthmo-lobectomiy in $9.1 \%$ of cases (1/11).

Pathological examination of the parts operating entered into a parathyroid adenoma in $63.6 \%$ of cases (7/11), parathyroid hyperplasia in $36.4 \%$ of cases (4/11).

The postoperative were simple in $81.8 \%$ of cases (9/11), complicated in $18.2 \%$ (2/11). These 2 complications were a compressive cervical hematoma that was evacuated in emergency by a drain (Redon) and a surgical site infection. We have not recorded lesion of the lower laryngeal nerve.

There has been no death (mortality zero).

After 6 months postoperative the rate of PTH has been dosed in 10 patients. He was in the standard desired in $50 \%$ of cases $(5 / 10)$, superior in $50 \%$ of cases $(5 / 10)$.

\section{Discussion}

Limitations of the study:

We didn't the scintigraphy, surgery was performed on the basis of knowledge in anatomy.

We did neither the extemporaneous examination of the operating room nor the per operative dosage of the parathyroid hormone.

The sex ratio for women in our study (7.2) is consistent with the data in the literature [2] [3] [4].

The female is a risk factor in the occurrence of secondary hyperparathyroidism in chronic renal insufficient patients [1]. The relative risk is multiplied by 2 due to a hypersensitivity to the action of PTH associated with ovarian dysfunction (anovulation and amenorrhea) predisposing to bone consequences rise in hyperparathyroidism secondary [5].

All patients in our study conducted a hemodialysis. Hemodialysis has been practiced in $90 \%-100 \%$ by the authors [1] [2] [5]. The reference value of PTH in this study was $15-65 \mathrm{pg} / \mathrm{ml}$, and the average rate parathyroid hormone was $2413.51 \mathrm{pg} / \mathrm{ml}$ as shown in Table 2 . 
The diagnosis of hyperparathyroidism secondary to renal failure chronic is suspected by clinical and radiological arguments, but the diagnostic confirmation was based on the blood dosage of parathyroid hormone (PTH); top two to nine times the upper reference value of laboratory [1] [2] [5].

Surgery is reserved for situations in which the rate of PTH is higher than 1000 $\mathrm{pg} / \mathrm{ml}$, associated with resistance to medical treatment and clinical signs.

This definition has been shared by all of the authors [1] [2].

The surgical technique of choice was the 7/8th parathyroidectomy.

Several authors have suggested that the 7/8th parathyroidectomy as the technique of choice for a first surgery and the total parathyroidectomy with auto transplantation of parathyroid tissue according to Wells after failure of the subtotal parathyroidectomy [1] [2] [6].

The most frequent histological type was the parathyroid adenoma in $63.6 \%$ of the cases. There were $36.4 \%$ of parathyroid hyperplasia.

The histological type of parathyroid hyperplasia is correlated with the severity of hyperparathyroidism secondary [2].

The rate of post operative complications is higher in our study (18.2\%).

This rate is statistically identical to that of Magali $(10.8 \%, p=0.08)$ [5] but higher than H. Sayad (3.5\%, p < 0.05) [2] and Alek Sander $(3.5 \%, \mathrm{p}<0.05)$ [3].

This difference can be explained by our short experience in parathyroid surgery.

The mortality rate was $0 \%$ in our study.

This rate is statistically identical to that of Magali $(1.7 \%, p=0.12)$ [5] but lower than H. Sayad (7.01\%, p < 0.05) [2] and Tsung Liang Da $(6.7 \%, \mathrm{p}<0.05)$ [6].

This statistical difference can be explained by the small size of our sample.

According to the results of biological balance (PTH) of 6 months post operative the failure rate of surgical treatment in our study was $50 \%$ (Table 3 ). It is high compared with literature data ranging from $3.50 \%$ to $42.85 \%$ [1] [2] [5].

This can be explained by the lack of diagnostic facilities including scintigraphy, which helps guide the surgical gesture with precision; as well as operating per dosage of PTH and frozen review that help the success of the surgical act.

\section{Conclusion}

Secondary hyperparathyroidism diagnosis is clinical, and radiological, but confirmation is biological (PTH Dosage). Surgery is indicated in cases of secondary. Hyperparathyroidism is resistant of medical treatment. Scintigraphy is now essential for the success of operative surgery as well as the dosage peroperative of the parathyroid hormone and frozen review of the operating room. The $7 / 8$ th parathyroidectomy is a therapeutic way course in the treatment of severe secondary hyperparathyroidism in the insufficient chronic renal.

\section{Authorization of the Ethics Committee}

We, undersigned, authors of this article give evidence that we received the au- 
thorization of the Ethics Committee for the realization of this study.

\section{Conflicts of Interest}

The authors state that there is no conflict of interest in the publication of this article.

\section{References}

[1] Lamyae, E. (2016) Traitement chirurgical de l'hyperparathyroïdie scondaire chez l'hémodialysé chronique (A propos de 7cas). Thèse Med. Maroc, $\mathrm{N}^{\circ} 052 / 16$.

[2] Sayad, H, Rifki Jai, S., Lakhloufi, A., Chihad, F., Bouzidi, A., Aghai, R., Tarras, F., Ramdani, B., Hachim, R., Benghanem, N.G., Zaid, D. and Ahazzam, J. (2008) Traitement chirurgical de l'hyperparathyroïdie secondaire des insuffisants rénaux: A propos de 57 cas. La Tunisie Médicale, 86, 140-143.

[3] Konturek, A., Barczyński, M., Stopa, M. and Nowak, W. (2016) Subtotal Parathyroïdectomie for Secondary Renalhyperthyroidism: A 20-Year Surgical Outcome Study. Langenbeck's Archives of Surgery, 401, 965-974. https://doi.org/10.1007/s00423-016-1447-7

[4] Murray, S.E., Sippel, R.S. and Chen, H. (2012) The Incidence of Concomitant Hyperparathyroidism in Patient with Thyroid Disease Requiring Surgery. Journal of Surgical Research, 178, 264-267. https://doi.org/10.1016/j.jss.2012.03.008

[5] Magali, F. (2005) Prise en charge chirurgicale de l'hyperparathyroïdie secondaire dans l'insuffisance rénale chronique: À propos de 230Tcas. Thèse Med France, $\mathrm{N}^{\circ} 10$.

[6] Tsung-Liang, M.A., et al. (2015) Parathyroidectomy Is Associated with Reduced Mortality in Hemodialysis Patients with Secondary Hyperparathyroidism. BioMed Research International, 2015, Article ID: 639587. 